\title{
Land-Cover Change Research at the U.S. Geological Survey-Assessing Our Nation's Dynamic Land Surface
}

\begin{abstract}
he U.S. Geological Survey (USGS)
recently completed an unprecedented, 27-year assessment of landuse and land-cover change for the conterminous United States. For the period 1973 to 2000, scientists generated estimates of change in major types of land use and land cover, such as development, mining, agriculture, forest, grasslands, and wetlands. To help provide the insight that our Nation will need to make land-use decisions in coming decades, the historical trends data is now being used by the USGS to help model potential future land use/ land cover under different scenarios, including climate, environmental, economic, population, public policy, and technological change.
\end{abstract}

Identifying historical land-cover change trends and their causes is essential for predicting potential future changes in land use. Population growth, policy changes, and increased pressures on natural resources will determine future landscape change, altering human resource requirements, as well as the landscape's potential to provide them.

U.S. Geological Survey (USGS) scientists recently completed an assessment of land-use and land-cover change for the conterminous United States. Scientists used the Landsat satellite image archive (http:// landsat.usgs.gov/) to analyze land-use and land-cover change between 1973 and 2000. Rates and trends in agricultural activities, timber harvesting patterns, expansion of developed areas, incidence of fire and other natural disturbances, modification of grasslands, and other changes have been estimated for five different image dates (1973, 1980, 1986, 1992, and 2000).

The analysis was conducted on all 84 ecoregions of the conterminous United States. Ecoregions were chosen as the best unit of analysis as they represent geographically unique landscapes with similar climate, plants and animals, and resource potential. Results from this historical analysis reveal a complex mosaic of change.

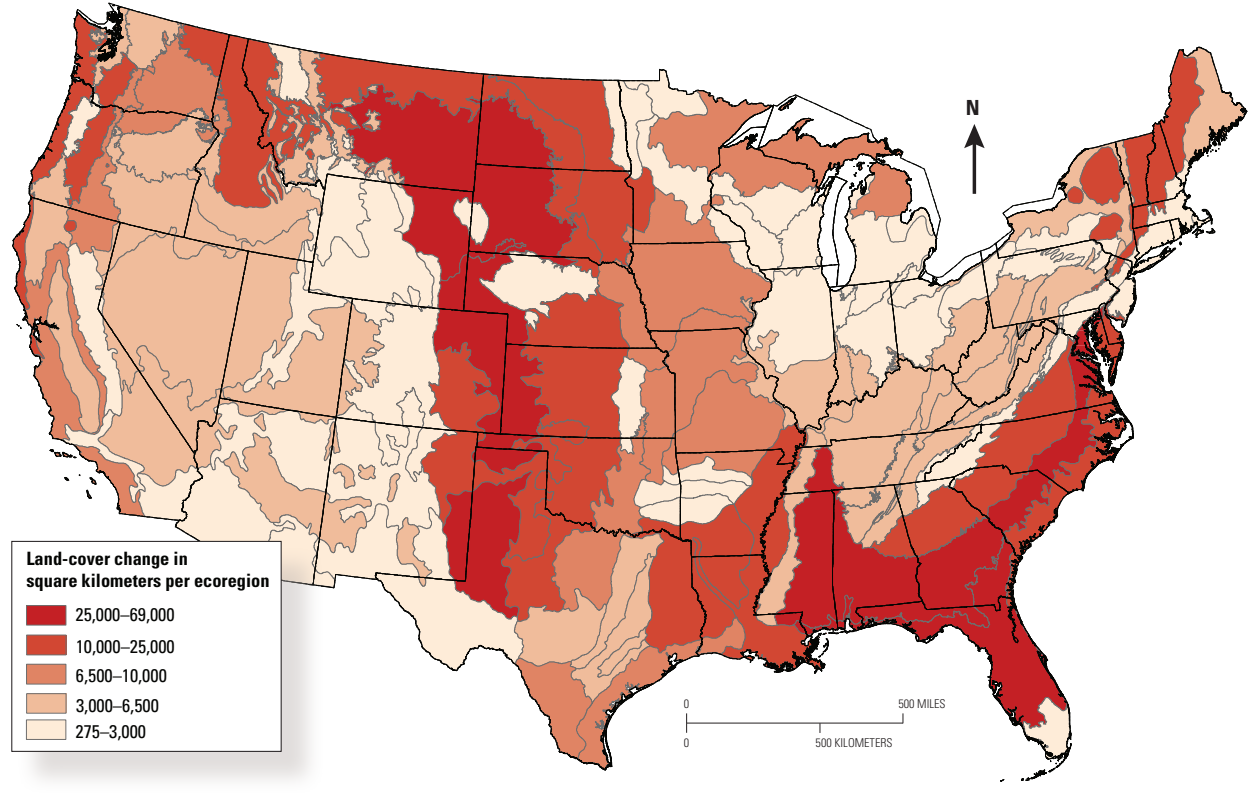

This map is one example of U.S. Geological Survey efforts to help provide the crucial information that our Nation will need to make land-use decisions in the coming decades. This map shows the overall "footprint" of land-cover change estimated for each of the 84 ecoregions in the conterminous United States between 1973 and 2000 . The footprint of change is the sum of all land-cover changes estimated in square kilometers per ecoregion. Ecoregions are outlined in grey. Warmer colors indicate areas where land-cover change has been greatest.

Ecoregions expressed distinct patterns across space and time in response to biogeophysical (biological, geological, and physical) and socioeconomic drivers of change. An estimated $8.6 \%$ of land cover changed in use at least once between 1973 and 2000. Developed land use increased by $33 \%$, while forests and agriculture declined by $4 \%$, and grassland/shrubland increased by $2 \%$.

Using this improved understanding of historical trends in land-cover change, the USGS can better provide decisionmakers with crucial information on where future land change is likely to occur.

\section{Land-Cover Trends}

The USGS Land-Cover Trends Web site (http://landcovertrends.usgs.gov/) provides a searchable database of remotely sensed imagery, land-cover and land-cover-change estimates for the 84 ecoregions in the conterminous United States, and summary reports describing change in each ecoregion. USGS scientists are working to establish a comprehensive and integrated land-change monitoring system to provide systematic updates to the existing 27-year Land-Cover Trends dataset. This includes exploration of alternative methodologies for expanding the land-change history timeline to the 2005, 2010, and 2015 time periods and beyond. Pilot studies are currently underway to determine best approaches and potential methodology changes for continued, costeffective data delivery. Existing data are being run through vigorous quality assessments to ensure their usability and portability for scientists, policymakers, and the general public

\section{Drivers of Land-Cover Change}

USGS scientists are analyzing how environmental, institutional, political, technological, demographic, and economic drivers determine the temporal and spatial distribution of land-use and land-cover change. Field observations, socioeconomic data, and biogeophysical variables are also being examined to identify local, regional, and broader scale forces driving landscape change. Identifying these forces will help 
decisionmakers make better informed choices to mitigate landuse impacts on carbon and nitrogen cycles, erosion, water quality, and atmospheric and other environmental processes.

\section{Consequences of Land- Cover Change}

Current research is focusing on the consequences of land-use and land-cover change on Earth's surface albedo (reflectance), snow cover, radiative forcing (a measure of the balance between the energy absorbed by the Earth's atmosphere and surface and the energy reradiated back to space), and the carbon cycle (cycling of carbon to and from the atmosphere, oceans, soils, freshwater, sediments, and Earth's crust and mantle). The type and distribution of land cover also affects regional weather and climate patterns. USGS scientists are working to determine which critical land uses and landscape variables have the greatest effect on the climate system and other ecosystem processes. Work has begun to analyze how forest-cover changes, such-as harvesting and regrowth, affect surface-water quality and availability.

\section{Modeling Scenarios for Land- Cover Change}

Modeling scenarios of future land-use and land-cover change is important to un-
Landsat Images Used to Estimate and Map Land-Cover Change
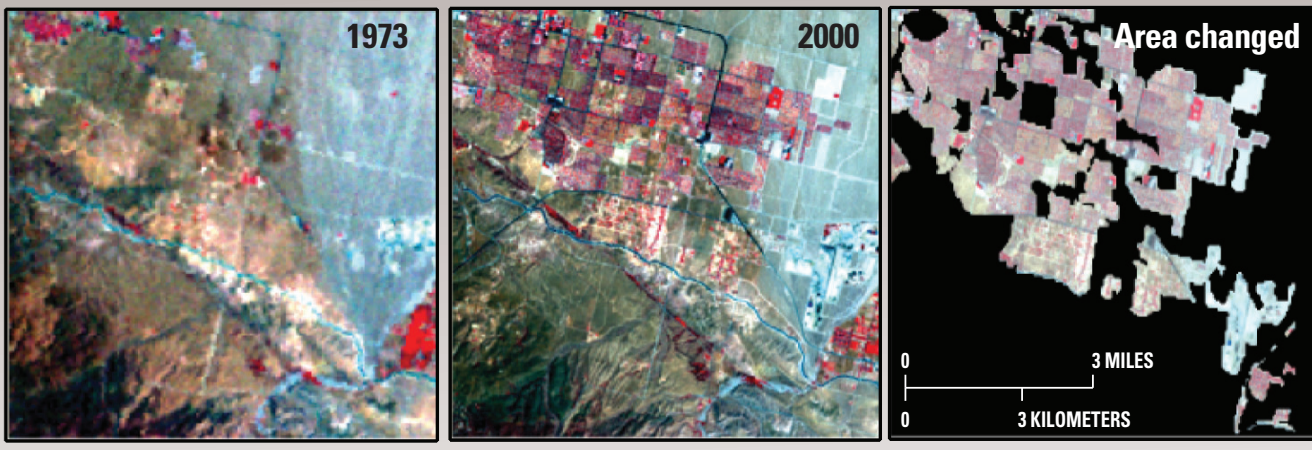

These satellite images show examples of land-cover change in the United States. U.S. Geological Survey scientists recently completed an unprecedented assessment of land-use and land-cover change for the conterminous United States for 1973 to 2000 using the Landsat satellite imagery archive. The top row shows (left to right) a 1973 Landsat Multispectral Scanner System (MSS) image and a 2000 Landsat Enhanced Thematic Mapper Plus (ETM+) image of Palmdale, California, as well as total area changed from 1973 to 2000 . Land-cover change is dominated by development and a mining operation in the east. Area changed image shows the final extent of all changed areas; areas that experienced no change are represented in black.

\section{Modeling Future Land-Cover Scenarios}
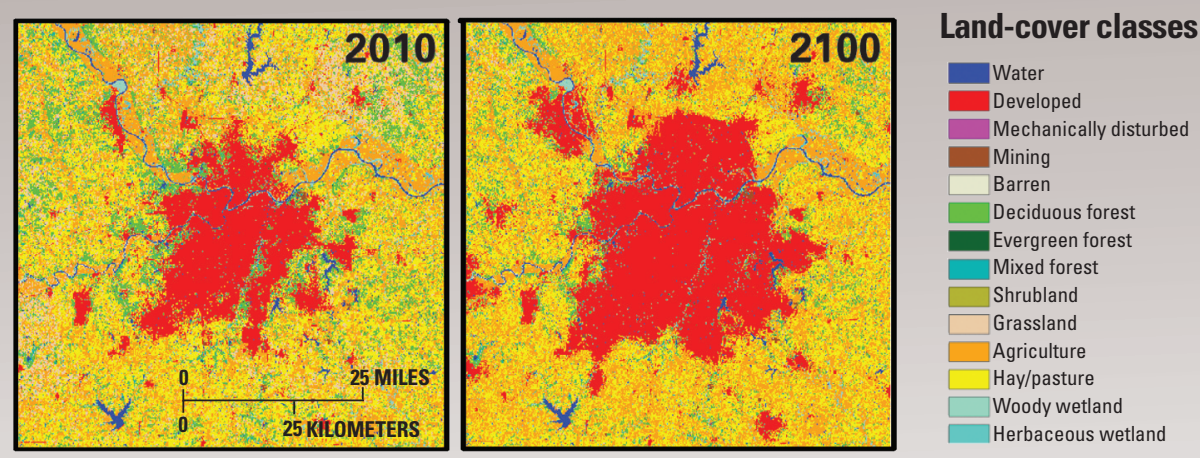

These images show land use and land cover for the greater Kansas City, Missouri, metropolitan area mapped in 2010 and modeled to the year 2100. The land-use modeling results are based on the A2 scenario from the Intergovernmental Panel on Climate Change Special Report on Emission Scenarios as developed by the U.S. Geological Survey Land-Cover Trends project. In the A2 scenario, economics are the driving force of change, along with intense fossil fuel use, low rates of technological innovation, and nearly 150 million more residents in the United States by 2050. In this example, increasing demand for land uses, such as agriculture and development, result in decreases in land-cover classes such as grassland, shrublands, and forest. on varying economic, population, technological innovation, and policy assumptions and were developed for use in resource planning, climate, and hydrologic modeling investigations.

The recently completed assessment of land-use and land-cover change for the conterminous United States is only part of USGS efforts to better understand the causes and consequences of land-cover change. USGS is continuing productive collaborations with policymakers, public land managers, and local communities to help ensure that they have the crucial information they need to make informed decisions about ongoing and future land-use choices. into the future. These scenarios are based

Tamara S. Wilson

Edited by James W. Hendley II Graphics and layout by Judy Weathers

For more information, contact: Benjamin M. Sleeter U.S. Geological Survey 345 Middlefield Road, MS 531

Menlo Park, CA 94025

Tel. (650) 329-4350

bsleeter@usgs.gov

http://landcovertrends.usgs.gov/ This Fact Sheet and any updates to it are available at

http://pubs.usgs.gov/fs/2011/3080/ 